\title{
Influences of Theory and Practice in the Development of Servant Leadership in Students
}

\author{
Jennifer Massey \\ Assistant Dean for Student Learning \& Engagement \\ Baylor University \\ Waco, TX 76798 \\ Tracey Sulak \\ Coordinator for Student Life Research \& Assessment \\ Baylor University \\ Waco, TX 76798 \\ Rishi Sriram \\ Assistant Professor of Higher Education \& Student Affairs \\ Baylor University \\ Waco, TX 76798
}

\begin{abstract}
This paper explores the extent to which the leadership knowledge, skills, and abilities of upper-year student leaders on one private, United States college campus developed as a consequence of their education and experience as an extended orientation leader. Findings reveal that compared to leadership education in the classroom, leadership development is limited by experiences that do not include intentional reflection. We identify key elements in pedagogical frameworks that support and impede the leadership development of students and propose strategies to enhance the learning outcomes established for leadership development.
\end{abstract}

\section{Introduction}

For more than 100 years orientation programs have sought to support new students as they transition from high school to college by connecting them with upper-year undergraduate student mentors (Busby \& Strumpf, 2006). Today, orientation, and increasingly extended orientation, programs are common on university and college campuses across North America (Pike \& Kuh, 2005). In fact, $96 \%$ of colleges have some type of orientation program for new first-year or transfer students (Barefoot, 2005).

Although orientation programs vary in design, scope, and scale (Daddona \& Cooper, 2002), they all serve as a conduit to the higher learning community (Busby, Gammel, \& Jeffcoat, 2002). For many new students orientation programs 
are an important introduction to the academic community. They are designed to connect new students to campus and provide information about institutional expectations and supports (Busby, Gammel, \& Jeffcoat, 2002; Moxley, NajorDurack, \& Dumbrigue, 2001; Upcraft \& Farnsworth, 1984).

Despite the prominence of orientation programs on university and college campuses, relatively little empirical research has comprehensively examined the outcomes associated with these initiatives (Mayhew, Vanderlinden, \& Kim, 2010). Indeed, the breadth and scope of orientation programs has created challenges in providing consistent and reliable information about the influence of such programs on student success and retention. Of the limited research examining orientation, the majority has focused on the learning outcomes of new students. These studies found students who attend orientation report stronger social connections, greater commitment to the institution, and have higher retention rates and academic achievement at the end of their first year (King \& Wessell, 2004; Pascarella, Terenzini, \& Wolfe 1986; Upcraft \& Farnsworth, 1984).

The learning outcomes associated with orientation programs, however, extend beyond those attributed to new students. Universities typically employ upper-year undergraduate students as orientation leaders or mentors to facilitate the orientation experiences of the incoming class. One of the primary reasons cited by universities for using upper-year undergraduate students is to develop the leadership skills and abilities of student leaders. While student leadership development is frequently stated as an outcome of orientation programs, little research examining the leadership development of student leaders has been conducted.

With this study we seek to address this gap in the literature by critically examining the leadership development of students participating in a leadership course and a subsequent experiential learning program (i.e., leadership opportunity). We explore the extent to which the leadership knowledge, skills, and abilities of student leaders at one private, research intensive, U.S. university developed as a consequence of their education and experience as an extended orientation leader. We examine the integration of servant leadership and experiential learning in the development of student leaders participating in extended orientation programs. The findings of this study will inform student leadership educators and provide evidence for measurable outcomes related to leadership development in an experiential setting. We also identify key elements in pedagogical framework that support and impede the leadership development of students, and propose strategies to enhance the learning outcomes established for leadership development. 


\section{Experiential Learning and Leadership Development}

The extended orientation program in this study was founded on the concept of servant leadership, a philosophy of leading that embraces service to others (Keith, 2008). The primary directive for a servant leader is that the leader is called to serve first, and second to lead. Rather than embracing the power structure inherent in hierarchical leadership positions, the measure of a servant leader's capacity is found in the growth of the followers (Greenleaf, 2002; Keith, 2008). Although empirical research in the field of servant leadership is lacking, many conceptual models have been proposed. The components of the models vary, but central to each is the qualities of empathy, foresight, stewardship, calling, trust, credibility, and most importantly service (Barbuto \& Wheeler, 2006; Farling, Stone, \& Winston, 1999; Liden, Wayne, Zhaa, \& Henderson, 2008; Sendjaya, Sarros, \& Santora, 2008). These models posit that service behaviors are used to build trust in leadership skills, which thereby leads to a position of influence built upon service to the followers (Joseph \& Winston, 2005).

Servant leaders must embody attributes of a servant such as vision, honesty, trust, appreciation of others, and service (Russell \& Stone, 2002). When a servant leader demonstrates these core beliefs consistently over time, the message inspires followers' trust (Joseph \& Winston, 2005). Servant leaders remain servants even after reaching a position of power. Leadership is a learning process for servant leaders, as opposed to a set of in-born characteristics (Brown \& Posner, 2001). Leadership is, therefore, developed, relational, contextual, and worthy of rigorous self-examination and study. It is through the process of leading that servant leaders make mistakes, and through intensive reflection upon these mistakes, servant leaders engage in learning opportunities that help refine their leadership style. As a result, servant leaders emerge as more equipped for future leadership developed through practice and reflection.

In this study we use Kolb's (1984) experiential learning model as a theoretical framework for assessing the leadership development process of student leaders. Kolb applied experiential components to learning theories to conceptualize a cyclical pattern of conception, action, concrete experience, and reflection (see Figure 1). This type of learning is flexible and mutable; ideas are intended to change as experiences change. Kolb's model can begin at any point in the cycle, as long as the emphasis is on the cyclical nature of the model. Thinking about concepts, theories, and ideas occurs during the abstract conceptualization phase. After learning about the theory or concept, learners enter the action stage which involves putting theory and concepts into practice. The next stage includes reflection and feeling. During this phase the theory and action are compared to assess whether the learner needs to modify the theoretical knowledge to fit the experience or if the learner can accept the actual experience as a match to the existing theory (Kolb, 1984). Once a learner determines a method for reconciling theory and practice a reflection period occurs. Reflection may be considered an incubation period for thinking through new problems and considering the 
previous learning. Reflection leads into another iteration of the cycle by integrating together practice and theory.

Figure 1

Kolb's (1984) Learning Cycle

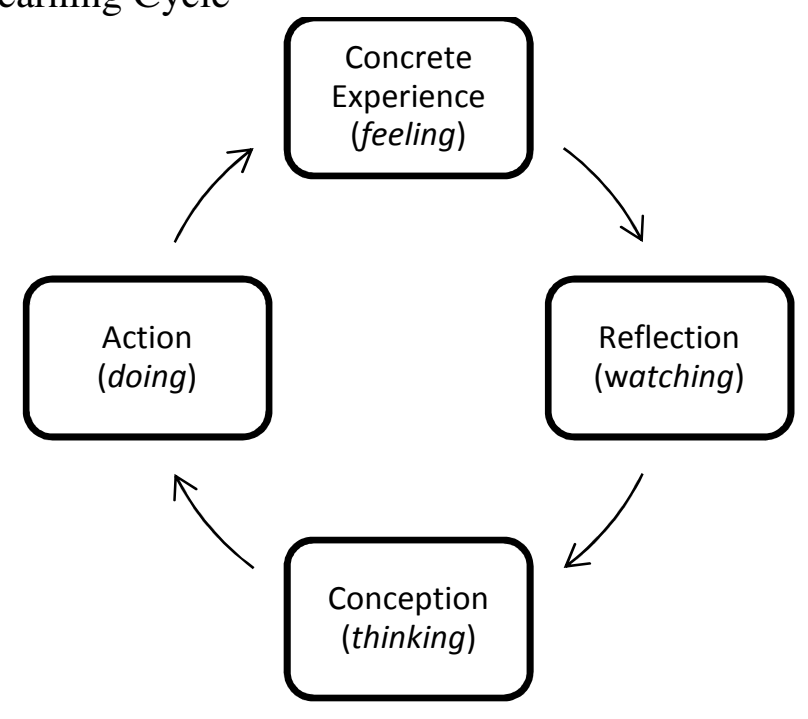

In the extended orientation program examined in this study, students began the learning cycle at the conception stage of Kolb's 1984) cycle. All student leaders were required to register and pass a leadership development course prior to their summer leadership experience. The course required students to demonstrate comprehension of the leadership development theories taught in the course. The focus of the leadership course was the role of a servant leader and students were taught the behaviors and values associated with the leadership style.

All four stages most likely occurred in the classroom, but its emphasis was the conception stage of Kolb's (1984) model. After completion of the course, students served as leaders during an extended summer orientation program. Again, although multiple stages could have occurred in the summer experience, the emphasis was the action stage of learning. Student leaders were charged with helping new students begin their transition to campus and to the expectations of higher education. Student leaders were expected to effectively communicate to incoming students the core values of the institution's new student experience connection, identity, reflection, friendship, and tradition.

\section{Measuring Student Leadership Development}

Four research questions guided our examination of the leadership development of students serving as extended orientation leaders. These questions were related to instrument development, comparing leadership outcomes before and after the leadership course, comparing leadership outcomes after the course to the 
leadership practice experience, and evaluating the strengths and weaknesses of leadership education and practice. They were:

- Does an instrument designed to measure college student leadership outcomes meet psychometric standards for construct validity and reliability?

- To what extent did the classroom experience contribute to growth in leadership outcomes for student leaders of the extended orientation program?

- To what extent did the leadership practice component contribute to leadership outcomes when compared to the classroom experience?

- What are the strengths and weaknesses of the design of leadership education and practice for student leaders of extended orientation programs?

The demographics of the sample may be found in Table 1.

Table 1

Demographics of student leaders

\begin{tabular}{|c|c|c|c|}
\hline & $\begin{array}{l}\text { Baseline } \\
(n=239)\end{array}$ & $\begin{array}{c}\text { After Formal } \\
\text { Instruction/Conception } \\
\quad(n=197)\end{array}$ & $\begin{array}{c}\text { End of } \\
\text { Program/Concrete } \\
\text { Experience } \\
(n=32) \\
\end{array}$ \\
\hline \multicolumn{4}{|l|}{ Gender } \\
\hline Male & $43 \%(n=103)$ & $44 \%(n=87)$ & $66 \%(n=21)$ \\
\hline Female & $57 \%(n=136)$ & $56 \%(n=110)$ & $35 \%(n=11)$ \\
\hline Age & 18.8 years $(.9)$ & 19.0 years $(.9)$ & 19.6 years $(.7)$ \\
\hline \multicolumn{4}{|c|}{ Demographic Characteristics } \\
\hline First generation & $19 \%(n=38)$ & $19 \%(n=38)$ & $3 \%(n=1)$ \\
\hline $\begin{array}{l}\text { Held at least } 1 \text { leadership } \\
\text { position during formal } \\
\text { instruction }\end{array}$ & $81 \%(n=194)$ & $85 \%(n=167)$ & $88 \%(n=28)$ \\
\hline $\begin{array}{l}\text { Belonged to } 2 \text { or more } \\
\text { student organizations }\end{array}$ & $75 \%(n=179)$ & $80 \%(n=158)$ & $81 \%(n=26)$ \\
\hline \multicolumn{4}{|l|}{ Race or Ethnicity } \\
\hline Caucasian/White & $68 \%(n=167)$ & $68 \%(n=133)$ & $75 \%(n=24)$ \\
\hline Hispanic & $12 \%(n=27)$ & $12 \%(n=23)$ & $13 \%(n=4)$ \\
\hline African American/Black & $12 \%(n=26)$ & $12 \%(n=24)$ & $6 \%(n=2)$ \\
\hline $\begin{array}{l}\text { Asian American/Pacific } \\
\text { Islander }\end{array}$ & $4 \%(n=7)$ & $4 \%(n=7)$ & $3 \%(n=1)$ \\
\hline Other/ Multiracial & $4 \%(n=12)$ & $5 \%(n=10)$ & $3 \%(n=1)$ \\
\hline
\end{tabular}

Note: Due to attrition, the sample declined over the course of the study.

The instrument used in this study was designed by a faculty member who teaches leadership development in order to measure elements of servant leadership. Three professionals who work with student leaders provided feedback on the content validity of the instrument. The survey consisted of a custom student leadership survey containing 38 Likert-type questions designed to measure different aspects of servant leadership development including theoretical knowledge, leadership 
style, leadership competence, and interpersonal skills. Each item was scored from 1 - not representative at all to 7 - extremely representative.

All students who were accepted to serve as extended orientation leaders participated in a pre-test measure of their leadership knowledge, skills, and experiences. This provided baseline information, which was subsequently compared with two repeat measures administered at the following stages of Kolb's (1984) learning cycle - (a) after the formal class (conception), (b) at the end of the program. To address the variation in participation at each time point, two independent analytical procedures were conducted. The first procedure was after the formal class experience and the second at the end of the program.

To determine construct validity, exploratory factor analysis in SPSS was used to establish composite variables representing elements of servant leadership from the leadership survey. Factor analysis is a procedure used to reduce a large number of manifest or measured variables into subsets of latent or unmeasured variables that may be representative of specific constructs (Field, 2009). This analysis was selected because the instrument had no prior psychometric data. Exploratory factor analysis was conducted on all 38 original survey items using alpha factoring with promax rotation to maximize the reliability of resulting factors. Alpha factoring with a Kaiser's criterion of 1 was used because the study utilized repeat-measures to determine growth in servant leadership development. When using repeat-measures, the higher reliability of the factors allows the researcher to draw conclusions about changes in factor values. Promax rotation was selected because the latent variables (i.e., depth of relationships, personal calling) used to formulate servant leadership are likely to be related (Keith, 2008).

All the assumptions for factor analysis were met. The correlation matrix from the analysis did not show any variables with correlations over .6 which supports the absence of multicollinearity. This was confirmed by Bartlett's Test of Sphericity, $\chi^{2}(406)=4222.97, p<.001$ which indicated all correlations were significantly greater than 0 . Combined with the results of the correlation matrix and the value of the determinant of the $R$-matrix (0.00094), the Bartlett's Test of Sphericity supports the use of factor analysis (Field, 2009). The Kaiser-Meyer-Olkin value $(\mathrm{KMO}=.88)$ as well as the individual item values $(\mathrm{KMO}>.5)$ also supported the use of factor analysis with the sample. Paired sample $t$-tests were used to test the difference between means for individuals at the baseline and after the formal classroom instruction on each of the five factors created through exploratory factor analysis and the sixth factor, servant leadership. The same procedure was applied to the means after formal classroom instruction and the means at the end of the experience. A paired sample $t$-test was used because it accounts for the lack of independence between scores from a pre- and posttest on the same individual. As multiple $t$-tests were used, a Bonferroni correction was applied to ensure the cumulative or familywise error rate was below .05 (Field, 2009). A Bonferroni correction creates a more conservative test for significance and increases the likelihood of rejecting a true effect, also known as a Type II error (Field, 2009). 


\section{Results}

The exploratory factor analysis resulted in five factors with eigenvalues over Kaiser's criterion of 1 and the five factors accounted for $40 \%$ of the variance. The scree plot was ambiguous showing inflexions at two factors as well as five factors. Table 2 shows the factor loadings for the five-factor solution after promax rotation. The items retained for each factor suggest that factor 1 represents recognition of strengths in self and others, factor 2 represents depth of relationships, factor 3 represents community and leadership, factor 4 represents recognition of individual differences, and factor 5 represents a personal calling. An additional factor of servant leadership was added to the five factors created through factor analysis. The additional factor was not supported by the factor analysis, but contained content relevant to the current study and was supported by the servant leadership literature. The items associated with servant leadership were important to assess given the framework of the intervention course. 


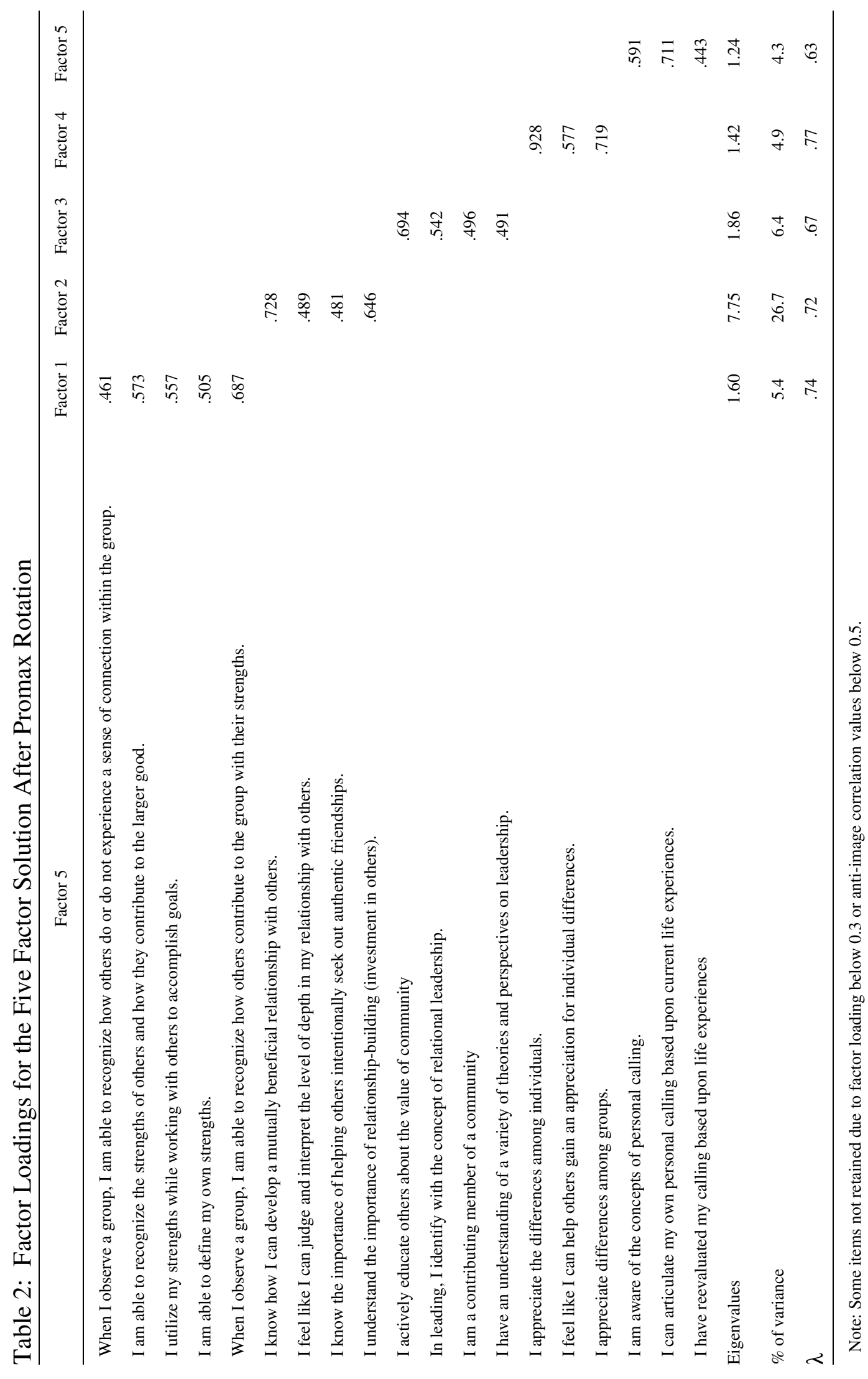


The items associated with servant leadership were important to assess given the framework of the intervention course. Since the items were not retained through the factor analysis, there is a possibility the items measure more than one construct. The five factors retained from the factor analysis in addition to the constructed factor of servant leadership may provide information about the changes occurring in the participants over the course of the intervention. The means and standard deviation for the variables retained after the factor analysis are reported in Table 4 by Kolb's (1984) stages and Table 3 reports the same information for the constructed factor of servant leadership.

Table 3

Items Used to Create Servant Leadership Factor

Item

In leading, I identify with the concept of servant leadership.

Servant leadership influences my decision making when approached with leadership situations.

I apply the knowledge I have gained about leadership to practical experiences as I lead at Baylor.

I apply the knowledge I have gained about leadership to practical experiences in my life.

Since coming to this institution, I feel my leadership capabilities have progressed.

I see that it is my duty to mentor other leaders and help them develop their leadership skills.

I have mentored other leaders to help them develop their leadership skills.

As a leader, I see the value of practicing reflection in my learning process.

I have identified some practices of reflection that work well for me.

\begin{tabular}{|c|c|c|}
\hline 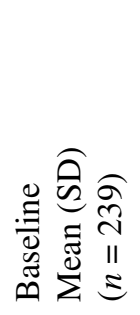 & 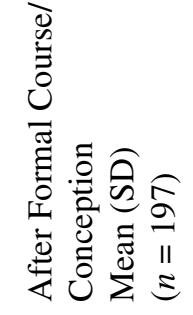 & 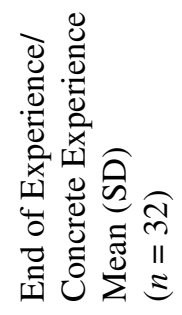 \\
\hline $6.0(1.1)$ & $6.2(1.0)$ & $5.7(1.3)$ \\
\hline $5.7(1.0)$ & $6.0(1.0)$ & $5.6(1.3)$ \\
\hline $5.6(1.1)$ & $6.1(1.0)$ & $6.2(0.7)$ \\
\hline $5.8(1.0)$ & $6.1(0.9)$ & $6.3(0.7)$ \\
\hline $5.8(1.2)$ & $6.4(0.9)$ & $6.8(0.4)$ \\
\hline $5.2(1.2)$ & $5.9(1.0)$ & $5.8(1.2)$ \\
\hline $4.7(1.5)$ & $5.2(1.3)$ & $5.0(1.4)$ \\
\hline $5.7(1.1)$ & $6.1(1.0)$ & $5.9(1.1)$ \\
\hline $5.0(1.4)$ & $5.8(1.1)$ & $5.7(1.1)$ \\
\hline .78 & & \\
\hline
\end{tabular}

Note: Scale from 1 - Not representative at all to 7 Extremely representative. 


\section{Table 4}

Descriptive Statistics for Leadership Survey Items Retained After Factor Analysis

Item

I am a contributing member of a community.

I appreciate differences among individuals.

I feel like I can help others gain an appreciation for individual differences.

When I observe a group, I am able to recognize how others do or do not experience a sense of connection within the group.

I actively educate others about the value of community.

I appreciate differences among groups.

I understand the importance of relationship-building

(investment in others).

I know how I can develop a mutually beneficial relationship with others.

I feel like I can judge and interpret the level of depth in my relationships with others.

I know the importance of helping others intentionally seek out authentic friendships.

I have an understanding of a variety of theories and perspectives on leadership.

In leading, I identify with the concept of relational leadership.

I am aware of the concept of personal calling.

I can articulate my own personal calling based up current life experiences.

I have reevaluated by calling based up current life experiences.

I am able to define my own strengths.

I am able to recognize the strengths of others and how

they contribute to the larger good.

I utilize my strengths while working with others to accomplish goals.

When I observe a group, I am able to recognize how others contribute to the group with their strengths.

Note: Scale from 1 - Not representative at all to 7 - Extremely representative.

The means and standard deviations for the variables included in each stage of the study may be found in Table 2. Results of the paired samples $t$-tests may be found in Table 5. Significant differences after the Bonferonni correction were found between pretest and posttest (before and after the leadership course) scores on the following factors: servant leadership, community and leadership, individual differences, and personal calling. No significant difference was found for the 
recognition of strengths factor and the depth of relationship factor. However, prior to the Bonferroni correction, significant differences were also found in recognition of strengths in self and others $(p=.026)$, as well as in depth of relationships, $p=.010$. In addition, no significant changes were found between the posttest and end of experience means on any factor, but growth was observed in the following factors - (a) recognition of strengths in self and others, (b) depth of relationships, (c) recognition of individual differences, and (d) personal calling. To determine the practical significance of the changes in the statistically significant factors of servant leadership, effect sizes were calculated using $r$ and are reported in Table 5. The effect size values may be interpreted as a 0.10 as a small effect, 0.30 as a medium effect, and 0.50 as a large effect (Kirk, 1996). Effect sizes were not included for non-significant findings.

Table 5

Results of Paired Samples $t$-tests for Factors From the Leadership Survey

\begin{tabular}{lll}
\hline Factor & $\begin{array}{l}\text { Baseline to End of Formal } \\
\text { Instruction }\end{array}$ & $\begin{array}{l}\text { End of Formal Instruction } \\
\text { to End of Program }\end{array}$ \\
\hline $\begin{array}{l}\text { Servant Leader } \\
\text { Recognition of strengths in self }\end{array}$ & $\begin{array}{l}t(50)=-5.66^{* * *} ; r=.60 \\
\text { and others }\end{array}$ & $t(29)=0.15$ \\
Depth of relationships & $t(29)=-1.63$ \\
$\begin{array}{l}\text { Community and leadership } \\
\text { Recognition of individual }\end{array}$ & $t(50)=-2.68$ & $t(29)=-0.51$ \\
differences & $t(50)=-4.90^{* * * ; *} ; r=.57$ & $t(28)=0.22$ \\
Personal calling & $t(29)=-0.19$ \\
\hline Note: The asterisks may be interpreted as follows: $* p<.05 ; * * p<.01 ; * * * p<.001$.
\end{tabular}

\section{Discussion}

\section{Conception through Classroom Instruction}

Kolb's (1984) learning cycle proposes four key stages in the experiential learning process. As mentioned prior, these four stages overlap in development processes and cannot be strictly segregated. However, different components of educational programming in college can each emphasize a different stage of the learning cycle. We conceptualized our study accordingly. Analysis from this study first demonstrated that the instrument we utilized to measure student leader learning outcomes was both valid for the current purpose and reliable. Further analysis revealed that the formal classroom instruction contributed to the leadership development of the extended orientation leaders. We found that the classroom instruction, which represented the conception stage in Kolb's learning cycle was particularly effective. Student leaders grew in their understanding of a variety of theories and perspectives on leadership with an emphasis on relational and servant-leadership. The instructional course introduced the theory and practice of servant leadership. This finding supports Eyler's (2002) argument that formal classroom instruction is an effective approach to teaching leadership theory. More specifically, students who have received formal instruction on a leadership theory 
consequently interpret their actions and others reactions through that theoretical lens. In the context of this study, course material focused on servant leadership and there was a significant positive change in students' understanding of that theory $(t(50)=-5.66, p<.001, \mathrm{r}=.60)$. This $(r=.60)$ is a large effect size (Cohen, 1988). It indicates that $36 \%$ of the growth in student knowledge may be attributed to the formal class instruction, which reflects the conception stage of Kolb's (1984) learning cycle. This indicates that the conception stage of the learning cycle emphasized by the leadership course was highly effective for producing leadership development in student leaders.

\section{Concrete Experience for Extended Orientation Leaders}

While the focus of the classroom instruction was on the development of student leaders through knowledge, the intention of the summer experimental component was to continue student leader development through the application of theory. In this study, however, their learning appeared to stagnate. Student leaders grew in theoretical knowledge from the course component but did not continue to grow in their understanding and application of servant leadership. This is indicated by the non-significant change between conception and concrete experience $(t(29)=$ $0.15, p>.05)$. In fact, student leader scores on the factor related to theoretical knowledge actually decreased between these two stages in Kolb's (1984) learning cycle.

\section{Reflection as Part of the Experience}

One explanation for lack of continued development during the experiential component is that the intentional focus of the experience did not include reflection on either the concrete experience itself or the prior classroom experience. The reflection most often used in experiential components includes sharing impressions and feeling, but not an intentional link to the academic learning applied in the field experience (Eyler, Giles, \& Schmiede, 1996). In the program studied here, the focus of the experience shifted from the development of student leaders to the transition of the new students they were serving. Indeed, the experiential component included very little intentional reflection, which according to Kolb (1984) is a key stage in the learning cycle.

An important discovery from this research is that learning tasks requiring construction of knowledge may benefit from experiential components, but the components need to include intentional reflection. Reflection is a critical part of any experiential learning initiative. The quantity and quality of reflection effects what students are able to know, do, or value at the end of their experience (Eyler, 2002). In the program examined in this study, formal reflection during the experiential component was limited to debriefing. Student leaders participated in a short group debrief every morning and one two-hour debriefing at the end of the program. These debriefs lacked some strong pedegological components of reflection. They were conducted by a different instructor each time which limited 
growth that is accomplished by consistency (Densten \& Gray, 2001; Hatton \& Smith, 1994). Also, debriefs focused on the well-being of the student leaders rather than including an intentional engagement of leadership development which limited the generation, documentation, and deepening of learning (Ash \& Clayton, 2009). Although this amount and type of reflection may have been beneficial to students in other ways, it did not serve to enhance student leaders' understanding of theories of servant leadership.

While student leaders' did not deepen their understanding and application of servant leadership through the experiential component, their understanding and application of their personal calling did increase. Previous research indicated students do not make connections between service experiences and academic study unless the links are purposefully described (Eyler, 2002). In this extended orientation program during the active learning stage of Kolb's (1984) model, student leaders facilitated small group discussions exploring personal calling and well-being. This informal type of reflection helped student leaders apply and practice their understanding of personal calling. The difference between the mean scores for personal calling after the formal instruction and at the end of the program was -1.16 , indicating the last score was higher than the prior score. The student leaders continued to grow showing higher values for personal calling after the classroom and experiential component (see Table 5). This demonstrates the impact of informal reflection during and after the experiential component and reinforces both the need and the potential for additional formal reflection that helps students make links between the classroom learning and the practical experience.

\section{Limitations}

The use of self-report for developmental and cognitive gains by college students has been criticized due to the low correlations between the self-reported gains and direct measurement (Bowman \& Seifert, 2011). The data for the current study was collected through self-report which may lead to an inaccurate measure of students' development in leadership skills. According to Bowman and Seifert, students who strongly agree or strongly disagree have the lowest correlations between actual gains and reported gains. The students in the current study tended to score at the strongly agree end of the spectrum and, as such, may be less likely to accurately report leadership gains.

In addition, due to attrition the number of students participating in the baseline was much higher than the number of students completing the final iteration. This made the results more difficult to interpret. For example, the students choosing to respond to the follow up collection may differ on significant variables when compared to students who chose to drop out of the study. This may skew the results of the study because the students choosing to participate at each time point may differ significantly from those who choose not to participate.

Notwithstanding these limitations, this study provides useful insight into the application of Kolb's model to servant leadership development. 


\section{Conclusions and Recommendations}

Experiential learning programs require intentional educational interventions throughout the learning cycle. In the current study the most significant growth in student leader development occurred when the most intentional educational interventions were present. Table 5 displays the results of the paired $t$-tests. Those results support significant changes during the classroom instruction, but not during the experiential component. The lack of growth during the experiential component may be related to stagnation and an incomplete rotation of Kolb's (1984) learning circle. For example, the reduced growth during the experiential may be related to the lack of intentional educational interventions during the experiential component. Further research examining student leadership development through experiential learning would benefit from using Kolb's model as an assessment framework.

Kolb's (1984) learning cycle provides a strong theoretical basis for examining the design and outcomes of experiential leadership development programs. On college campuses leadership development programs frequently adopt a loose interpretation of experiential learning pedagogy. Findings from this study demonstrate that for these programs to be most effective, program design must include intentional instruction at each phase of the learning cycle. When instruction was most intentional, the learning was the greatest. As the focus of the program shifted from student leaders to the students being served, the leadership development of those involved flattened out. Leadership development programs that employ experiential approaches to learning should include more formalized connections between theory and practice. For example, student leaders may benefit from using a journal during the active stage that includes prompts requiring students to explore the connections between classroom learning and their leadership practice. Incorporating such intentional reflection into the learning cycle should significantly improve leadership development on college campuses. As the body of research examining pedagogies that facilitate student leadership development continues to grow, the extent to which experiential learning contributes to leadership development will become more evident. 


\section{References}

Ash, S. L., \& Clayton, P. H. (2009). Generating, deepening, and documenting learning: The power of critical reflection in applied learning. Journal of Applied Learning in Higher Education, 1, 25-48.

Barbuto, J. E., \& Wheeler, D. E. (2006). Scale development and construct clarification of servant leadership. Group Organization Management, 31, 300-326.

Barefoot, B. O. (2005). Current institutional practices in the first college year. In M. L. Upcraft, J. N. Gardner, \& Associates (Eds.), Challenging and supporting the first-year student: A handbook for improving the first year of college. San Francisco: Jossey-Bass.

Bowman, N. A., \& Seifert, T. A. (2011). Can college students accurately assess what affects their learning and development? Journal of College Student Development, 52, 270-290.

Brown, L. M., \& Posner, B. Z. (2001). Exploring the relationship between learning and leadership. Leadership \& Organizational Development Journal, 22, 274-280.

Busby, R. R., Gammel, H. L., \& Jeffcoat, N. K. (2002). Grades, graduation, and orientation: A longitudinal study of how new student programs relate to grade point average and graduation. The Journal of College Orientation and Transition, 10, 45-50.

Busby, R., \& Strumf, G. (2006). The role of orientation programs; CAS standards contextual statement. In L.A. Dean (Ed.), CAS professional standards for higher education (266-273). Washington, DC: Council for the Advancement of Standards in Higher Education.

Cohen, J. (1988). Statistical power analysis for behavioral sciences $\left(2^{\text {nd }}\right.$ ed.). Hillsdale, NJ: Lawrence Erlbaum.

Daddona, M. F., \& Cooper, D. L. (2002). Comparison of freshman perceived need prior to and after participation in an Orientation Program. NASPA Journal, 39, 300-318.

Densten, I. L., \& Gray, J. H. (2001). Leadership development and reflection: what is the connection?. International Journal of Educational Management,15(3), 119-124.

Eyler, J. (2002). Reflection: Linking service and learning-linking students and communities. Journal of Social Issues, 58, 517-534. 
Eyler, J., Giles, D. E., \& Schmiede, A. (1996). A practitioner's guide to reflection in service-learning. Nashville: Vanderbilt University.

Farling, M. L., Stone, A. G., \& Winston, B. E. (1999). Servant leadership: Setting the stage for empirical research. Journal of Leadership Studies, 6, 49-72.

Field, A. (2009). Discovering statistics using SPSS ( $3^{\text {rd }}$ ed.). Newbury Park, CA: Sage.

Gardner, \& B. O. Barefoot (Eds.), Challenging and supporting the first-year student; a handbook for improving the first year of college (pp. 47-63). San Francisco: Jossey-Bass.

Hatton, N., \& Smith, D. (1994). Facilitating Reflection: Issues and Research.

Joseph, E., \& Winston, B. (2005). A correlation between servant leadership, leader trust, and organizational trust. Leadership \& Organization Development Journal, 26, 6-22.

King, T. M., \& Wessel, R. D. (2004). Impact of admitted student programs on matriculation and retention. Journal of College Orientation and Transition, 11, 49-51.

Kirk, R. (1996). Statistics: An introduction (5 ${ }^{\text {th }}$ ed.). Belmont, CA: Thomson.

Kolb, D. A. (1984). Experiential Learning: Experience as the source of learning and development. Englewood Cliff, NJ: Prentice Hall.

Komives, S. R., Lucas, N., \& McMahon, T. R. (2007). Exploring leadership, for college students who want to make a difference. $\left(2^{\text {nd }}\right.$ ed.). San Francisco: John Wiley and Sons.

Liden, R. C., Wayne, S. J., Zhaa, H., \& Henderson, D. (2008). Servant leadership: Development of a multidimensional measure and multi-level assessment. The Leadership Quarterly, 19, 161-177.

Mayhew, M. J., Vanderlinden, K., \& Kim, E. (2010). A Multi-Level Assessment of the Impact of Orientation Programs on Student Learning. Research in Higher Education, 51(4), 320-345.

Moxley, D., Najor-Durack, A., \& Dumbrigue, C. (2001). Keeping students in higher education: Successful practices and strategies for retention. London, UK: Kogan Page. 
Pascarella, E., \& Terenzini, P. (1979). Interaction Effects in Spady's and Tinto's Conceptual Models of College Dropout. Sociology of Education, 52, 197210.

Pascarella, E. T., Terenzini, P., \& Wolfe, L. (1986). Orientation to college and freshman year persistence/withdrawal decisions. Journal of Higher Education, 51, 60-75.

Pike, G. R., \& Kuh, G. D. (2002). A typology of student engagement for American colleges and universities. Research in Higher Education, 46, 185-209.

Rosenthal, R. (1991). Meta-analytic procedures for social research (revised). Newbury Park, CA: Sage.

Russell, R. F., \& Stone, A. G. (2002). A review of servant leadership attributes: Developing a practical model. Leadership and Organization Development Journal, 23, 145-157.

Sendjaya, S., Sarros, J. C. \& Santora, J. C. (2008). Servant leadership: Its origin, development, and application in organization. Journal of Leadership and Organizational Studies, 9, 402-424.

Upcraft, M. L., \& Farnsworth, W. M. (1984). Orientation programs and activities. New Directions for Student Services, 25, 27-38. 


\section{Author Biographies}

Jennifer Massey serves as Assistant Dean for Student Learning and Engagement and teaches in the School of Education and the Honors College at Baylor University. Her international research experience and interests include the geographies of education, global citizenship, curricular and co-curricular integration and assessment methodologies. She current serves on the editorial board of the Journal of Student Affairs Research and Practice, as a reviewer for the Canadian Journal of Higher Education, and as the External Relations Chair for Student Affairs Assessment Leadership (SAAL).

Tracey N. Sulak, Ph.D., has a doctorate in Educational Psychology from Baylor University. She currently serves as the Coordinator for Student Life Research and Assessment in the Office of Student Learning and Engagement at Baylor University. Her research interests are learning disabilities, assessment, and educational environments. She has multiple publications and presentations in each of these areas. She is currently a member of the American Educational Research Association, the Association for Psychological Science, and the American Montessori Society. Her educational experiences include teaching in public and private educational settings as well as serving as an instructor in the special education program at Baylor University.

Rishi Sriram, Ph.D., serves as Assistant Professor and Program Coordinator of the Higher Education and Student Affairs graduate program at Baylor University. $\mathrm{He}$ also directs a minor in leadership studies and teaches leadership to undergraduate students. His research interests include student affairs practice, collaboration between academic and student affairs, and college student retention, engagement, achievement, and development. He currently serves on the editorial board of the Journal of Student Affairs Research and Practice, the Journal of the First-Year Experience and Students in Transition, the Journal of College and University Student Housing, and as Director of Research for the Texas Association of College and University Student Personnel Administrators (TACUSPA). 